\title{
ARTE SONORA E EMERGÊNCIA
}

SOUND ART AND EMERGENCE

Ianni Luna

UnB (Universidade de Brasília) / SEEDF

Resumo: Este artigo relaciona o conceito de emergência em sistemas complexos à proposições estéticas desenvolvidas no âmbito da arte sonora. Para tanto serão elaboradas intersecções conceituais interdisciplinares entre arte, ciência e tecnologia, com o intuito de estabelecer confluências capazes de potencializar os sentidos poéticos de uma arte generativa capaz de endereçar problemáticas de autoria e colaboração no cerne da discussão entre humano e não humano em artes.

Palavras-chave: arte e tecnologia, arte sonora, emergência, performance sonora, arte generativa.

Abstract: This article relates the concept of emergence in complex systems to aesthetic propositions developed within the scope of sound art. For this purpose, interdisciplinary conceptual intersections between art, science and technology will be elaborated, in order to establish confluences capable of enhancing the poetic senses of a generative art capable of addressing problems of authorship and collaboration at the heart of the discussion between human and non-human in arts.

Keywords: art and technology, sound art, emergency, sound performance, generative art. 
Frente ao massivo crescimento da pesquisa científica pós-industrial, diversos setores intelectuais teceram inúmeras críticas em relação aos fins e meios de tal desenvolvimento face à realidade social e histórica das populações globais. Internas à seara científica, tais críticas também problematizaram metodologias e abordagens específicas à produção de conhecimento dos paradigmas epistemológicos vigentes até então. A "epistemologia da complexidade" é um arcabouço teórico que articula diferentes instâncias do pensamento crítico contemporâneo às diversas áreas do saber, no sentido de realizar uma revisão crítica multidisciplinar em relação ao paradigma de conhecimento científico tradicional (MORIN, 1991).

$\mathrm{Na}$ "complexidade" são reconsideradas as características de linearidade de cadeias explicativas e o reducionismo das metodologias de pesquisa das ciências ditas exatas - analisar as partes em sua menor fração de maneira isolada. O "pensamento complexo" propõe uma abordagem que rejeita a disjunção, a redução e a racionalização; operações intelectuais tão fundamentais para o pensamento determinista científico moderno ocidental. Para Morin (1991), os fenômenos não são simples, eles são compostos por emaranhados de dados, em contextos específicos e sujeitos a uma série de fatores causais. O grande desafio do pensamento complexo, então, é estabelecer uma articulação entre os mais diversos campos de pesquisas e disciplinas, de forma a dar vazão a uma maneira de fazer ciência que problematize a ocorrência de insuficiências e resultantes carências do pensamento simplificador.

O "pensamento complexo" tenta, dessa maneira, operacionalizar novas narrativas científicas que possam abarcar o enredamento dos acontecimentos, seus elementos constituintes e sua interação mútua dentro de sistemas espe- cíficos. A partir do "pensamento complexo" lançamos olhares para as artes enquanto campo do saber, reconhecendo afinidades e semelhanças. A interdisciplinaridade e a abertura para paradoxos e instabilidades conceituais mantêm ambos em constante dinamismo interno e em interessado debate externo. É por meio da atividade estética em arte e tecnologia que tecemos portanto, o enredo deste artigo, por articular de maneira suficientemente aberta a relação entre humano e não-humano, em especial a relação entre humanos e máquinas.

O "pensamento complexo" está intimamente ligado à teoria dos sistemas, e dessa maneira serve como aparato teórico a partir do qual relacionaremos fenômenos estéticos/poéticos do campo das artes, a fenômenos emergentes em sistemas definidos. A teoria geral dos sistemas (TGS), elaborada, entre outros, pelo biólogo austríaco Bertalanffy na segunda metade do século XX, busca desenvolver princípios unificadores que atravessam verticalmente os universos particulares das diversas ciências, com o objetivo de instaurar processos de conhecimento mais abrangentes e interconectados. Tendo sido amplamente utilizada em diferentes setores de nossa sociedade, desde a administração de empresas até a cibernética; a teoria dos sistemas reconhece a necessidade de se observar os fenômenos a partir de um entendimento que integra as diversas partes de sua estrutura e funcionamento de maneira a reconhecer padrões em escalas de diversas magnitudes.

Um sistema constitui-se de elementos interdependentes entre si, que interagem e transformam-se mutuamente. Há sistemas fechados e abertos, sendo, estes últimos, foco de nosso interesse na medida em que representam o que de fato experienciamos. Os sistemas abertos são sistemas complexos compostos de vários elementos que interagem entre si, além de sofre- 
rem interações com o ambiente onde estão inseridos. Desta forma, a interação gera realimentações que podem ser positivas ou negativas, ${ }^{1}$ criando assim uma auto regulação regenerativa, que por sua vez cria novas propriedades que podem ser benéficas ou maléficas para o todo independente das partes (BERTALANFFY, 1975). Tais interações é que definirão as caraterísticas dos sistemas definidos, gerando informações imprevistas e específicas ao seu funcionamento global. Essa abordagem difere em muito das metodologias de pesquisa pautadas nos princípios analíticos cartesianos. O conjunto geral de um sistema complexo abarca suas partes, e vai além, dinamizando processos causais e sofisticando a experiência do todo fenomênico.

\section{Emergências Generativas}

$\mathrm{O}$ artista e pesquisador estadunidense Philip Galanter vem desenvolvendo trabalhos interdisciplinares que vinculam modelos protótipos de sistemas complexos a aplicações estéticas multimídia. A partir de articulações conceituais entre a TGS (BERTALANFFY, 1975), a cibernética, a ciência cognitiva e experimentos computacionais em vida artificial; o pesquisador estabelece investigações em arte e tecnologia que derivam em intrincadas instalações que articulam artes visuais, música e arquitetura. A pesquisa de Galanter nos mostra a existência de um elemento fundamental que interessa às artes que é a habilidade dos sistemas complexos de gerar, ao longo do tempo, recorrências impossíveis de serem antecipadas. Essa habilidade é a emergência,

1 "O feedback negativo ocorre sob muitas formas e tamanhos. Você pode usá-lo em mísseis balísticos ou em circuitos integrados, neurônios ou vasos sanguíneos [...] de modo esquemático, envolve a comparação entre o estado atual de um sistema e o estado desejado, e a pressão sobre o sistema, numa direção que minimize a diferença entre os dois estados" (JOHNSON, 2003:103). função que se articula diretamente a questões fundamentais sobre a natureza da vida e os limites da ciência.

A emergência é a capacidade que tem um sistema complexo de fazer emergir comportamentos padrão a partir de uma grande quantidade de interações pequenas e muito simples (GALANTER, 2004). Qualquer sistema constituído por partes que apresentem algum grau de complexidade está propenso à emergência. São regras simples criando resultados complexos. Como um acontecimento, a emergência surge e apresenta elementos que não estavam previstos a partir do que já se sabia. É algo com o que se depara, uma surpresa, uma revelação.

O exemplo clássico é a colônia de formigas, um organismo que possui comportamentos claramente definidos, lógicos e coerentes, observáveis em duas escalas diferentes. Quando estudamos os padrões de cada formiga, vemos que cada uma tem necessidades, habilidades e respostas de feromônio que definem seu comportamento como inseto individual. Mas quando estudamos o comportamento coletivo da colônia, vemos padrões comportamentais sofisticados; a colônia atua como uma cidade, com fábricas, defesas e instalações de eliminação de resíduos. O que é notável é o fato de que esses padrões macro não são formados por meio de um design ou intenção central: eles não são mais do que subprodutos dos comportamentos locais auto-interessados dos indivíduos coletivamente. Esses comportamentos, aparentemente insignificantes no nível micro, formam um macro-organismo mais complexo quando vistos coletivamente (GALANTER, 2004, p. 7).

Historicamente, a emergência foi objeto de investigação copiosa em áreas como a biologia de insetos, a neurociência, a sociologia urbanística e a engenharia de software (JOHNSON, 2003). Com relação aos processos da consciência por exemplo, não se sabe com precisão como esse 


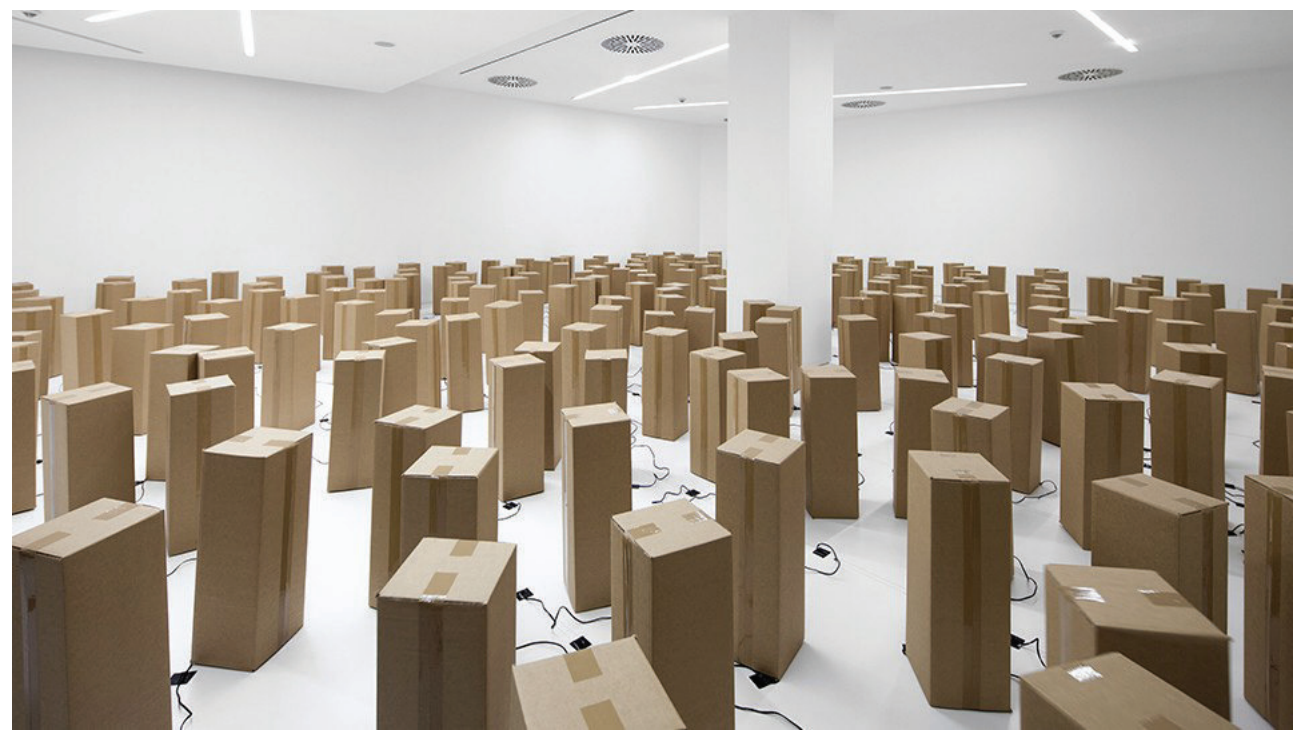

Figura 01: Zimoun, Untitled, 2015.1 Fonte: https:// www.zimoun. net/site/assets/ files/1104/zimoun2015-240-960x540px.960x540.jpg

comportamento de nível mais alto aparece, mas sabemos que "é invocado pelas interações de feedbacks locais de agentes inconscientes, pelo complexo sistema de adaptação que chamamos de mente humana. Nenhum neurônio individual é senciente e, de alguma forma, a união de bilhões de neurônios cria a autoconsciência" (JOHNSON, 2003, p. 151). A partir de intrincadas relações que estabelece com diferentes espectros da tecnologia em diferentes instâncias do saber, os sistemas de arte vêm abrangendo o entendimento da emergência enquanto elemento precipitador de novas estéticas.

Esse espaço intermediário e indefinido de parcial ordem e parcial desordem, portanto, de imprevisibilidade, propiciado pela emergência, apresenta problemáticas importantes para a questão da autoria da obra de arte. A partir da noção de retroalimentação sistêmica, a emergência opera como poética a partir da qual proposições artísticas produzem efeitos circunstanciais de coautoria. No caso de experimentos em arte sonora, o sistema instaurado pelo/a artista recebe mais ou menos determinações de início, mas, a partir das interações estabele- cidas, em maior ou menor grau, adquire dinâmicas próprias. "Os comportamentos emergentes, assim como os jogos, vivem dentro dos limites definidos pelas regras, mas também usam esse espaço para criar algo maior do que a soma das partes" (JOHNSON, 2003, p. 135).

Em decorrência da morfogênese, ${ }^{2}$ a emergência opera resultados generativos, na medida em que suspende a noção tradicional de autoria e obnubila as fronteiras entre corpos, mentes, máquinas e humanidades. Sistemas estéticos complexos geram formações espontâneas a partir da abdicação de níveis de gerência, instaurando uma espécie de poética da emergência que se configura enquanto projeto artístico. "Entender a emergência sempre incluiu desistir de controle, deixar o sistema governar a si mesmo tanto quanto possível, deixá-lo aprender a partir de passos básicos" (JOHNSON, 2003, p. 175).

Na obra Untitled (Figura 01) o artista suiço Zimoun dispõe 240 caixas de papelão $(60 \times 20 \times 20 \mathrm{~cm})$ na ver-

2 "Morfogênese é a capacidade de todas as formas de vida de desenvolverem progressivamente corpos mais elaborados a partir de inícios incrivelmente simples" (JOHNSON, 2003, p. 11).
10 vídeo deste trabalho se encontra na página do artista. Disponível em: https://www.zimoun. net/. Acesso em Junho de 2020. 
tical e as espalha pela sala de paredes brancas. No interior das caixas, estão acoplados motores de corrente contínua que fazem soar, de maneira multiplicada em função da escala, uma massa sonora que extrapola em muito o som que cada item emite em isolamento. A fonte sonora nos é ocultada de maneira que nos colocamos a tarefa de imaginá-la, ou abstraí-la. A experiência sonora adquire sentidos próprios, se complexificando quando contrastada à sua materialidade minimalista no local de exibição. O som em repetição infinita perde suas características individuais para adquirir formações derivativas que excedem e transmutam o gesto inicial. O efeito conjunto de uma sonoridade diminuta, é agigantado exercendo força de emergência. As caixas parecem pequenos organismos em reação, que, em generatividade, acionam efeitos de sentido que perpassam o elemento operacional da unidade em direção a um sistema.

\section{Deixar os sons serem eles mesmos}

John Cage foi um compositor estadunidense cuja abordagem à composição foi profundamente influenciada pelas filosofias asiáticas, por meio da incorporação da idéia de uma música ditada pelo acaso e uma aproximação ao uso da tecnologia e de instrumentações não convencionais. Em suas obras identificamos uma abordagem radical baseada na improvisação e na construção aleatória de sons e, mais especificamente, em processos de composição baseados na valorização da existência singular dossons, no que têm deválidos por serem como são. "Música nova: nova escuta. Não é uma tentativa de entender algo que está sendo dito, pois, se algo estivesse sendo dito, os sons receberiam as formas das palavras. Apenas uma atenção à atividade dos sons" (CAGE, 2012, s/p, tradução nossa). ${ }^{3}$

3 Do original: "New music: new listening. Not an attempt to understand something that is being said, for, if something were being said, the sounds would be given the shapes of words. Just an attention to the activity of sounds" (CAGE, 2012, s/p).
Para Cage era fundamental "deixar os sons serem eles mesmos” (CAGE, 2012, s/p, tradução nossa). ${ }^{4}$ Há, em seu pensamento, sobretudo, uma ênfase no processo, na experiência, em permitir que sons, ruídos e silêncios ocorram como acontecimento estético. O fazer musical predomina em detrimento da permanência de um objeto artístico que acaba por mistificar-se. Esta concepção revela divergências em relação a uma abordagem estritamente autoral de composição, na qual a experiência sonora resulta de uma vontade pessoal original, apontando para a possibilidade de que qualquer som, ou sua ausência, possam ser considerados musicais, contanto que sejam propostos enquanto tal. Além disso há em Cage uma abertura para que as máquinas e instrumentos utilizados na composição e execução dos trabalhos sejam considerados sob a insígnia da co-autoria.

Uma noção importante para a arte generativa e, portanto, para as poéticas da emergência em arte sonora, é a criação com a colaboração de sistemas generativos não-humanos. O objeto e a máquina - em sentido amplo - tendem a constituir nuances dessa estética que, no acionamento de potencialidades tecnológicas, gera aberturas de sentido. A emergência ocorre quando um/a artista opta por ceder algum grau de controle a um sistema externo e o trabalho resulta em mais do que apenas a atuação de uma ou outra parte. São trabalhos nos quais elementos reais ou virtuais interagem entre si, originando eventos complexos e imprevistos pelo/a artista, expandindo os conceitos tradicionais de criação e autoria. "Ninguém seria capaz de dizer o que aconteceria apenas olhando o conjunto original de regras. Você tem que fazê - lo viver antes de compreender como funciona" (JOHNSON, 2003, p. 123, grifo do autor).

4 Do original: "Let the sounds be themselves" (CAGE, 2012, s/p). 


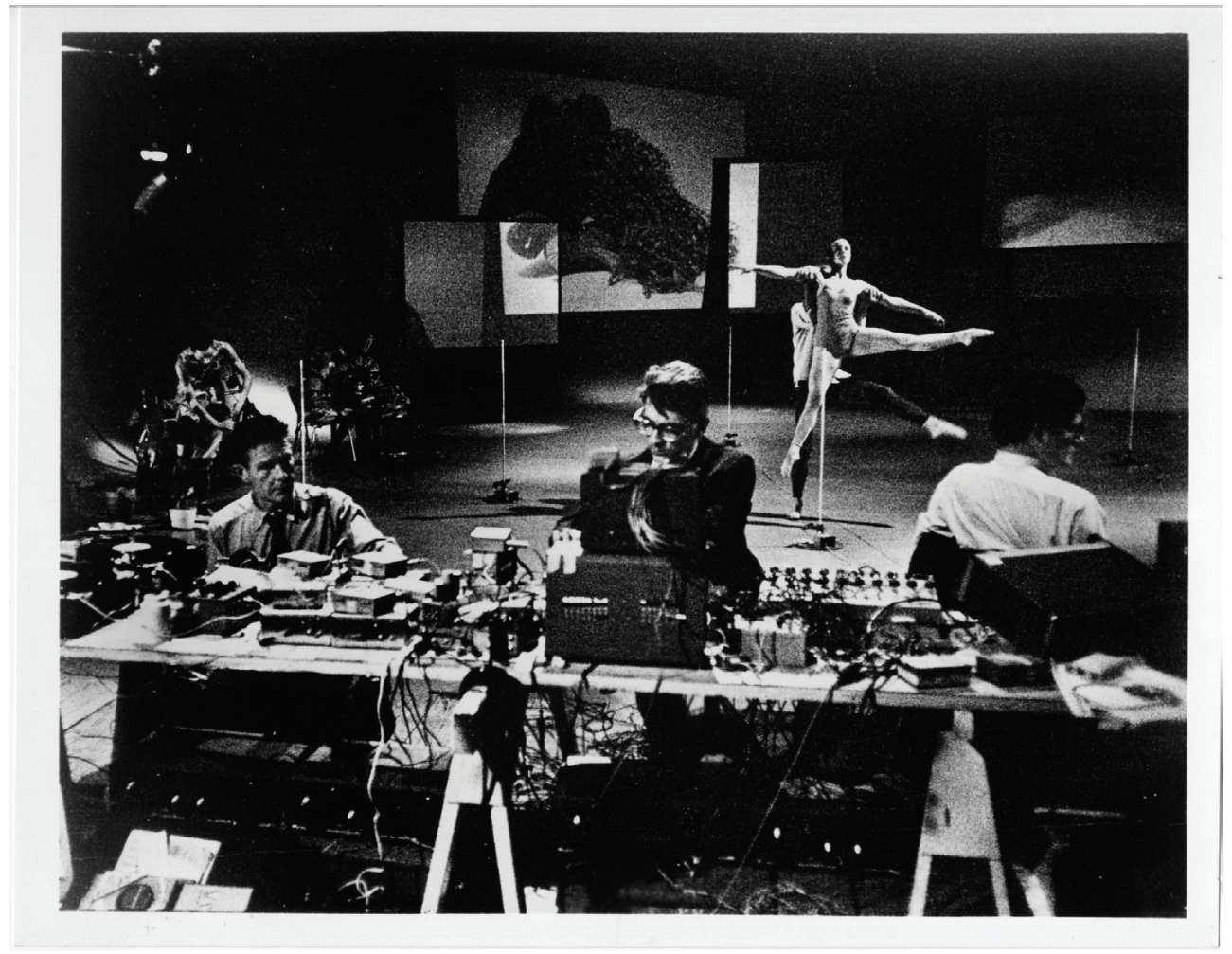

Figura 02: John Cage, Imaginary Landscape No. 1, 1939. Fonte: https://i.pinimg.com/ originals/fa/c9/27/fac92765b884ec8862df01d3333057e9.jpg

Dois tocadores de vinil de velocidade variável emitem gravações de tom senoidal enquanto um piano é parcialmente abafado em suas emissões sonoras e um prato chimbal de bateria é golpeado a intervalos irregulares. Imaginary Landscape No. 1 (Figura 02) é uma composição de John Cage que integra uma série de cinco peças que têm como elemento comum o uso de eletricidade (Imaginary Landscape No. 5 ocorreu em 1952). Ainda que não tenha sido pensada para ser performada ao vivo e sim, gravada em um estúdio de rádio para depois ser reprodu zida ou transmitida, esta composição marca o início de um interesse por composições eletroacústicas que utilizassem instrumentos eletrônicos. Aos poucos, a tecnologia musical permitiu que essas apresentações se dessem ao vivo, o que corroborou para o desenvolvimento de incipientes técnicas eletrônicas experimentais.
A partir da série Imaginary Landscape a eletricidade passa a ocupar lugar de destaque nas composições de Cage e esse fator está intimamente ligado à trajetória que a dinâmica entre sonoridades, maquinário e forças da natureza vão adquirindo em seus trabalhos. A questão da emergência aparece de maneira implícita no uso que o artista faz das circunstâncias que produzem e modificam ruídos e sinais sonoros, de maneira a atribuir parte da autoria da composição para o que era gerado ao vivo, sob os auspícios de acidentes e improvisos.

\section{Performance Sonora e Interatividade Maquínica}

Os primeiros instrumentos eletrônicos destinados à performance ao vivo, como o TeIharmonium em 1897, o Theremin em 1919, o Spharophon em 1924, o Ondes Martenot em 
1928 e o Trautonium em 1929, entre outros; são importantes antecedentes ao que corresponde à contemporânea performance sonora de música eletrônica ao vivo (ou Live Electronic Music ou, simplesmente, Live Electronics). No final dos anos 1950 e início dos anos 1960 é que ocorre uma transição mais efetiva das técnicas eletrônicas dos estúdios para a síntese ao vivo. A partir de 1964, Karlheinz Stockhausen, um dos idealizadores da música eletrônica alemã (elektronische Musik) entrou em um período de intensa pesquisa que geraram três importantes obras, Mikrophonie I, Mixtur e Mikrophonie II. Enquanto as composições anteriores empregavam principalmente amplificação, a inovação de Stockhausen era adicionar transformações eletrônicas por meio de filtragem, o que apagou a distinção entre música instrumental e eletrônica (TOOP, 2000).

O filósofo tcheco naturalizado brasileiro Willém Flusser escreve sobre as intrincadas relações entre cultura e materialidade nas sociedades tecnológicas contemporâneas através de analogias que marcam transposições epistemológicas que moldam nossas funções perceptivas. Partindo das tecnologias que foram forjadas ao longo do tempo como instâncias de mediação entre o humano e a natureza, Flusser estabelece uma espécie de cronologia histórica das técnicas. "As ferramentas imitam a mão e o corpo empiricamente; as máquinas mecanicamente; e os aparelhos, neurofisiologicamente" (FLUSSER, 2017, p. 36). A nossa relação com os aparatos tecnológicos moldariam assim, de maneira significativa, as experiências estéticas e as práticas poéticas no interior dos sistemas de arte.

No caso da arte sonora, as aproximações interdisciplinares se fazem perceber em estreita correspondência com as dinâmicas de composição e autoria veiculadas a tecnologias musicais. "Que a fronteira entre a música e as artes plásti- cas, sob o domínio da matemática, se dissolveria, já era, há muito tempo, esperado. 'Compor' é sinônimo de 'processar dados' e até mesmo para Pitágoras a lira e o triângulo já estavam próximos" (FLUSSER, 2010, p. 43). A mediação cultural que ocorre a partir das tecnologias que propiciam interações não apenas com a natureza e seus recursos, mas também entre pessoas; ocorre, não obstante, entre máquinas e códigos numéricos. Todo o sistema que constitui essas mediações, encontra na noção de 'interface' sua localização teórica. Cada vez mais a interação entre humanos e máquinas constrói sistemas coparticipativos, muitas vezes generativos, que adquirem efeitos de emergência a partir de um conjunto simples de regras. São processos que têm significado em resposta a uma estética que se dá em se "conhecendo como os fenômenos amorfos afluem às formas e as preenchem para depois afluírem novamente ao informe" (FLUSSER, 2017, p. 21).

Com os computadores, o uso de equipamentos digitais e softwares como as Estações de Trabalho Digital (DAWS) ampliaram e democratizaram tecnologias que expandiram significativamente os recursos disponíveis para experimentação e criação musicais. O compositor estadunidense Robert Gluck, diretor do estúdio de música eletrônica da Universidade de Albany nos EUA, há anos cria suas próprias interfaces de software para performance musical interativa e instalações multimídia. Gluck escreveu sobre a influência das transformações tecnológicas nas dinâmicas compositivas, em especial, enfatizando de que maneiras a Live Electronics retomava aspectos de presença e corpo que haviam se ausentado das práticas eletroacústicas de estúdio. "Uma ideia chave era que os gestos físicos eram os meios pelos quais os sons musicais são gerados e alterados. Isso representa uma restauração da asso- 
ciação entre fisicalidade e produção musical, um elemento importante na prática tradicional da performance" (GLUCK, 2007, p. 2, tradução nossa). ${ }^{5}$

A apresentação eletrônica ao vivo quebra muitas associações convencionalmente antecipadas entre movimentos específicos (como pressionar um arco na superfície de uma corda de violino) e o som resultante. De fato, qualquer som pode ser controlado por qualquer tipo de interface, criando uma nova ou expandindo uma associação convencional entre produção sonora e resultado sonoro (GLUCK, 2007, p. 2, tradução nossa). ${ }^{6}$

Na década de 1990, a partir da tecnologia portátil do laptop, surge a Laptronica, que é uma forma de música eletrônica ao vivo na qual os laptops são usados como instrumentos musicais (e uma combinação de muitos laptops pode ser usada para formar uma orquestra de laptops). ${ }^{7}$ É mais recente, mas cada vez mais frequente, que alguns sons sejam gerados e manipulados por codificação ao vivo (live coding), prática de programação interativa que combina composição algorítmica com improvisação. Normalmente, o processo de escrita do código é projetado no espaço da performance, trazendo um

5 Do original: "A key idea was that physical gestures were the means by which musical sounds are generated and changed. This represents a restoration of the association between physicality and music making, a major element in traditional performance practice" (GLUCK, 2007, p. 2). 6 Do original: "Live electronic performance breaks many conventionally anticipated associations between specific movements (such as pressing a bow on the surface of a violin string) and the resulting sound. In fact, any sound can be controlled by any type of interface, creating a new or expanding upon a conventional association between sound production and sonic outcome" (GLUCK, 2007, p. 2).

7 A Orquestra de Laptops de Brasília (BSBLOrk) por exemplo, foi fundada por Eufrásio Prates e conta com musicistas como Philip Jones e Ramiro Galas, atuando desde 2012. Disponível em: https://bsblork.gitlab.io/. Acesso em Junho de 2020. forte complemento visual.

À medida que a performance eletrônica ao vivo evoluiu, o design de instrumentos começou a desempenhar um papel integral em uma rede de elementos musicais que incluem estética, design e técnica de instrumentos e conteúdo. $\mathrm{O}$ design e a interação entre hardware, circuitos de computador e sua programação tornam-se parte do processo de composição. O novo sistema integrado de desempenho pode ser chamado de "interface' de desempenho, o veículo pelo qual um ser humano pode se envolver com sons e com os controladores que os promovem e alteram

(GLUCK, 2007, p. 3). ${ }^{8}$

Além do uso de DAWS e instrumentos preparados diversos, tecnologias de geração de som por síntese via equipamentos analógicos modulares passaram a ser reutilizados recentemente, em especial nos circuitos mais independentes de música experimental eletrônica. ${ }^{9}$ Com a síntese sonora, os sons são efetivamente criados e seus timbres podem ser transformados extensivamente, não apenas moldados, mas modulados. Essa plasticidade sonora pode ocorrer porque esses equipamentos são compostos por módulos separados, cumprindo diferentes funções. Os módulos são conectados com patch

8 Do original: "As live electronic performance evolved, instrument design began to play an integral role in a web of musical elements that include aesthetics, instrument design and technique, and content. The design and interplay between hardware, computer circuitry and its programming becomes a part of the compositional process. The new integrated performance system can be termed a performance 'interface', the vehicle by which a human being can engage with sounds and the controllers that enact and change them" (GLUCK, 2007, p. 3).

9 No passado, os sintetizadores modulares eram volumosos e caros. A partir dos anos 2010 houve um ressurgimento da popularidade de sintetizadores analógicos a partir de um uso mais experimental desses equipamentos. Um exemplo é a Bastl, pequena empresa italiana criada por dois artistas plásticos. Disponível em: https://bastl-instruments.com/. Acesso em Junho de 2020. 
Figura 03: Nguyễn + Transitory, Superbooth (frame de vídeo), 2020.1 Fonte: https://www. youtube.com/watch?v=6mtj153n4um

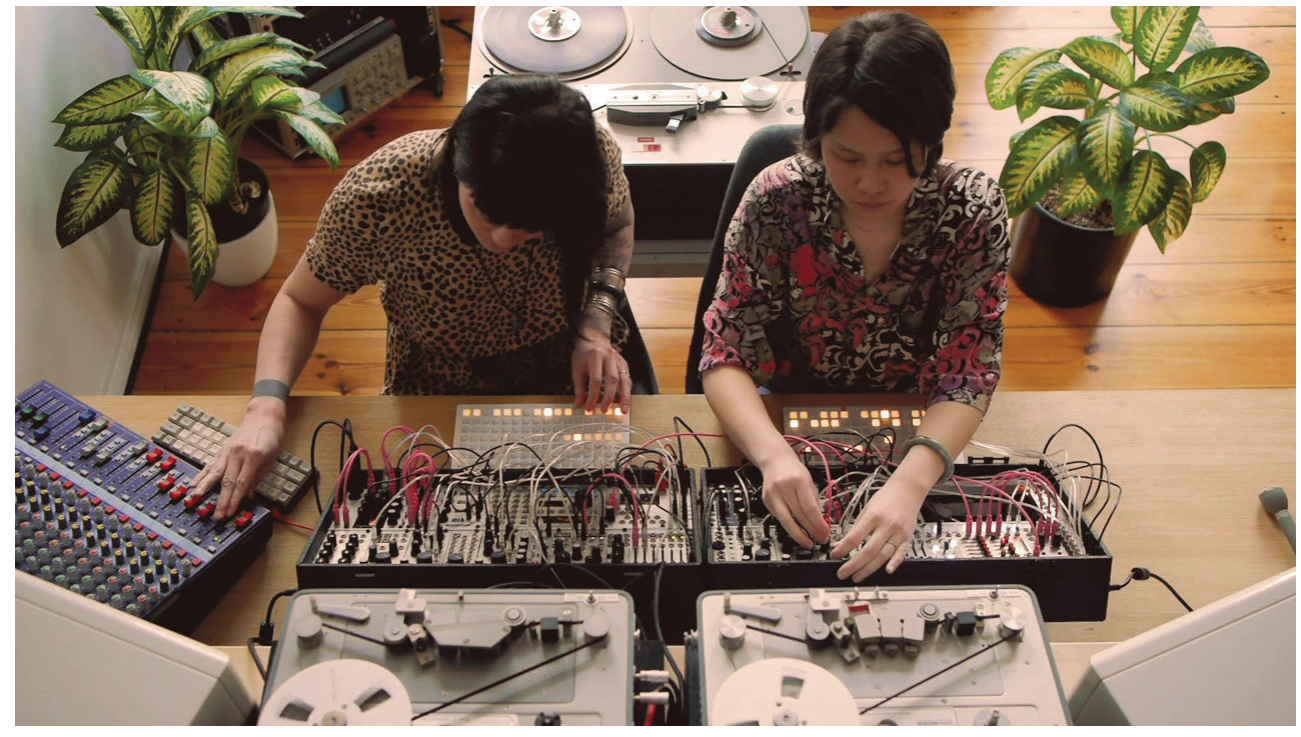

cords, um sistema de cabos que interliga partes dos módulos entre si para fechar um circuito que produza som. O patch corresponde ao conjunto dessas interligações, uma configuração de entradas e saídas que compõe um caminho específico para o sinal elétrico. É, portanto, um sistema complexo e como tal está sujeito à emergência.

Devido à natureza continuamente variável dos botões e controles, os sons produzidos por esse caminho (patch) são dificilmente replicados exatamente da mesma maneira, o que os empresta um caráter único, próprio e irrepetível, a cada vez que são gerados. Esse fator é um dos pontos estéticos de maior interesse na síntese sonora modular, pois a aproxima, junto às performances sonoras contemporâneas, de uma poética da emergência sonora generativa. Assim, a noção de autoria e de controle to-

1 Vídeo disponível em: https://www. youtube.com/watch?v=6mtj153n4uM. Acesso em Junho de 2020. tal das etapas do processo estético dão lugar a uma abordagem colaborativa com a máquina, os circuitos e a ambiência acústica, acionando uma espécie de organicidade vital às sonoridades que surgem.
A síntese digital geralmente envolve uma especificação numérica do valor do parâmetro desejado, embora sistemas mais recentes permitam que esses valores também sejam determinados de forma interativa. Em todos esses casos, pode-se dizer que o/a compositor/a compõe o som, bem como a estrutura dentro da qual ele é colocado (TRUAX, 2001, p. 151). ${ }^{10}$

Nguyễn Baly e Tara Transitory é um duo de Live Electronics (Figura 03) baseado em Berlim, que trabalha principalmente com sintetizadores modulares e tocadores de fita analógicos. Suas performances sonoras sondam como as frequências e a fisicalidade das vibrações se relacionam com miudezas sônicas na construção de ambientes, destacando um microcosmo que se revela por intimidades. Patches espontâneos são criados, a gerar sons contínuos, inter-

10 Do original: "Digital synthesis usually involves a numerical specification of the desired parameter value, though more recent systems allow such values to be determined interactively as well. In all of these cases the composer can be said to compose the sound as well as the structure within which it is placed (TRUAX, 2001, p. 151). 
ceptados regularmente por ruídos estridentes, curtos, que funcionam como mantenedores de um ritmo entrecortado. Aspectos emergenciais aos poucos são percebidos na medida em que o som é articulado junto a um discurso sonoro improvisado em constante generatividade. Uma espécie de escuta corporificada é invocada por meio de elementos de caráter tátil como o toque e as conectividades. São performances que estabelecem relações sonoras espaço-temporais com e entre ouvintes, via máquinas e corpos, fundindo-se em um comum sonoro.

As performances sonoras contemporâneas, em especial a Live Electronics, efetuam diálogos entre técnicas do passado e tecnologias do presente que estabelecem um entendimento da experiência sonora a operar em emergência. O trabalho de Zimoun (Figura 01), apresenta outrossim, instalações sonoras que, tangenciando esteticamente o minimalismo, efetuam sonoridades generativas que extrapolam os desígnios de seus elementos pontuais. "Esses trabalhos não se separam da localização, da INTERFERÊNCIA ou do ruído indesejado, mas abraçam esses elementos como uma importante fonte de composição" (LABELLE \& RODEN, 1999, p.7). ${ }^{11}$ São investigações sonoras muitas vezes efêmeras, que absorvem imperfeições e se conectam com a presença e a coparticipação dos contextos, equipamentos e audiência. Utilizam diversas interfaces tecnológicas em consonância (ou em dissonância) a uma miríade de efeitos e equipamentos híbridos. Não constituem repertórios com o intuito de serem reproduzidos sistematicamente ao vivo, o que as aproxima de uma prática familiar à performance art, desde a qual cada acontecimento estético é encarado de maneira fenomenológica e se cons-

11 Do original: "These works do not cut themselves off from location, INTERFERENCE, or unwanted noise, but rather embrace these elements as an important compositional source" (LABELLE \& RODEN, 1999, p. 7). titui como experiência singular.

São práticas despretensiosas na sua relação com as instituições musicais (a sala de concerto, a indústria fonográfica, a história da música). Elas se voltam para a performance ao invés da composição, para escuta ao invés do discurso analítico, para a integração entre os participantes ao invés da separação entre o palco e a platéia. Essas músicas vêm geralmente associadas a termos compostos, iniciados pela partícula "pós": pós-moderna, pós-digital, pós-punk, pós-colonialista. Elas marcam novamente o conflito das práticas artísticas quando tentam definir o seu lugar dentro da cultura (IAZETTA, 2015, p. 145).

Os trabalhos analisados neste artigo, num certo sentido, recuperam a relevância da presença como instituinte da experiência. E nisso realizam mediações entre sistemas naturais e culturais na medida em que estabelecem fronteiras permeáveis entre discursos da arte e da tecnologia, ao operarem como comentários críticos às prerrogativas de autoria que separam de maneira estanque as relações entre humano e não-humano em arte. São trabalhos replicáveis que nunca se repetem exatamente, acionando de maneira particular as funções entre arte sonora e emergência. Nas palavras de John Cage (2012, s/p, tradução nossa):12 "Como sempre prefiro concertos a discos de música instrumental. Que ninguém imagine que, ao possuir uma gravação, ele tenha a música. A própria prática da música [...] é eminentemente uma celebração de que possuímos nada".

12 Do original: "As ever, I prefer concerts to records of instrumental music. Let no one imagine that in owning a recording he has the music. The very practice of music [...] is a celebration that we own nothing" (CAGE, 2012, s/p). 


\section{Referências}

BERTALANFFY, Ludwig Von. Teoria Geral dos

Sistemas. São Paulo: Ed. Vozes, 1975.

CAGE, John. Silence: lectures and writings.

Versão digitalizada pelo Internet Archive, 2012 (primeira edição por Middletown, Connecticut: Wesleyan University Press, 1961). Disponível em: https://archive.org/stream/silencelecturesw1961cage/silencelecturesw1961cage_djvu.txt. Acesso em Junho de 2020.

FLUSSER, Vilém. A escrita. Há futuro para a escrita? São Paulo: Annablume, 2010.

O mundo codificado: por uma filosofia do design e da comunicação. São Paulo: Ubu Editora, 2017.

GALANTER, Philip. What is Generative Art? Complexity Theory as a Context for Art Theory, 2003. Documento online. Disponível em: http://www.philipgalanter.com/downloads/ ga2003_paper.pdf. Acesso em Junho de 2020.

What is emergence? Generative murals as experiments in the philosophy of complexity, 2004. Documento online. Disponível em: http://philipgalanter.com/downloads/ ga2004_what_is_emergence.pdf. Acesso em Junho de 2020.

GLUCK, Robert. Live electronic music performance: innovations and opportunities. In: Tav+, Music, Arts, Society, University at Albany, 2007.

IAZETTA, Fernando. Processos Musicais: entre a experimentação e a criação. In: Revista Resonâncias, NuSOM, USP, São Paulo, vol.19, n³6, 2015 (pp 141-146).

JOHNSON, Steven. Emergência: a vida integrada de formigas, cérebros, cidades e softwares. Rio de Janeiro, Jorge Zahar Ed., 2003.

LABELLE, Brandon \& RODEN, Steve (Eds.) Site of Sound: Of architecture and the ear. LOS Angeles: Errant Bodies Press/Smart Art Press, 1999.

MORIN, Edgar. Introdução ao Pensamento
Complexo, Lisboa: Instituto Piaget, 1991.

TOOP, David. Sonic Boom. In: Sonic Boom: the Art of Sound. London: Hayward Gallery Publishing, 2000.

TRUAX, Barry. Acoustic Communication. Westport, Connecticut: Greenwood Publishing, 2001.

\section{Ianni Luna}

Doutoranda em Arte e Tecnologia. Mestre em História (2006), bacharel em Artes Plásticas (2013), bacharel em Antropologia (2003); todos pela Universidade de Brasília (UnB). É professora de Artes da Secretaria de Educação do Distrito Federal (SEEDF). Faz parte do grupo de pesquisa em arte sonora Mopussara, junto ao Programa de Pós Graduação em Artes Visuais (PPGAV) na UnB. 